\title{
El Segismundo de Calderón y la segunda natureleza
}

Strosetzki, Christoph

First published in:

Anuario calderoniano, Nr. 4, S. 333 - 347, Iberoamericana, Madrid 2011,

ISBN 978-84-8489-598-5

Münstersches Informations- und Archivsystem multimedialer Inhalte (MIAMI) URN: urn:nbn:de:hbz:6-41489427259 


\section{EL SEGISMUNDO DE CALDERÓN Y LA SEGUNDA NATURALEZA}

Christoph Strosetzki

Romanisches Seminar

Westfalische Wilhelms Universität Münster

Bispinghof 3. Raum A 115

D-48143 Münster. Alemania stroset@uni-muenster.de

[Anuario calderoniano (ISSN: 1888-8046), 4, 2011, pp. 333-347]

¿Por qué fracasa Segismundo en La vida es sueño de Calderón durante su primera estancia en el palacio? ¿Por qué no es capaz de controlar sus pasiones, permitiéndose una serie de imprudencias, entre las que se llega a contar incluso una muerte, a pesar de haber tenido durante su encierro en la torre un buen maestro como Clotaldo? ¿Por qué carece de las virtudes más elementales de la moderación y el autocontrol? Todas estas preguntas tienen fácil respuesta: Segismundo no posee una segunda naturaleza. En lo sucesivo, se expondrá detalladamente la significación de la segunda naturaleza desde la Antigüiedad hasta el Siglo de Oro. Se concederá a las reflexiones teóricas del concepto, así como a su evolución en la Filosofia y en la Teología, un espacio mucho mayor que a su presencia en la literatura. Se mostrará brevemente que esta, efectivamente, existe, no sólo a través de los ejemplos de Mateo Alemán y su Guzmán de Alfarache o La vida es sueño de Calderón, sino también a través de algunos otros, que conformarán, en conjunto la introducción del presente estudio. 
De la importancia de la segunda naturaleza da cuenta Gracián en el Oráculo manual:

Fueran muchos muy personas si no les faltara un algo, sin el cual nunca llegan al colmo del perfecto ser. Nótase en algunos que pudieran ser mucho si repararan en bien poco. [...] En algunos se desea lo ejecutivo, y en otros lo reportado; todos estos desaires, si se advirtiesen, se podrían suplir con facilidad, que el cuidado puede hacer de la costumbre segunda naturaleza.

Poco importa, por tanto, una carencia, pues si se practica, señala Gracián, la costumbre acabará por convertirse en una segunda naturaleza. Calderón, en su pieza El divino Jasón, hace, por.boca de la idolatría, alabar a Medea como muestra de la segunda naturaleza, muy superior a la primera: «Perderá el sol su belleza, / volará la firme roca, / porque tienes en la boca / segunda naturaleza" (vv. 329-332).Y Lope de Vega asimismo habla de la segunda naturaleza en conexión con la costumbre y el hábito².

En la filosofia actual se plantea la cuestión de si también los animales o los seres inanimados pueden poseer una segunda naturaleza. De este modo, sentarse cuando recibe la orden de hacerlo puede convertirse en segunda naturaleza para el perro. John McDowell señala al respecto que "salvando el hecho de cómo se origina, la segunda naturaleza de los perros es exactamente igual que su primera naturaleza $)^{3}$. El oro puede adherirse a piedras o encontrarse en el río como conglomerado de metales preciosos en su primera naturaleza, mientras que adquiere una segunda naturaleza cuando se forja, dándosele forma de lingote, anillo u otras variantes. Cuando los niños crecen en medio de artefactos y tradiciones construidos social e históricamente,

${ }^{1}$ Gracián, Oráculo manual y arte de prudencia, p. 28.

2 «Aquí veréis el efeto que hace la ciencia, cuyo ejercicio honesto priva todo pensamiento ocioso, sacando el alma del cautiverio de la vil costumbre y rompiendo el hábito estrecho convertido en la misma vida, como segunda naturaleza. Veréis cómo se puede seguir la virtud, sin que espanten sus ásperos principios, y cómo no hay dificultad en ella que, esforzando la voluntad, no se acabe con la paciencia y consiga con la perseverancia», La Arcadia, p. 382.

${ }^{3}$ McDowell, 2000, p. 98: «Apart from how it originates, the second nature of dogs is just like their first nature». 
se benefician, a diferencia de Segismundo, del saber acumulado y de las prácticas de su grupo. Si la herencia biológica no se completa con la cultural, tanto la educación como la madurez resultan imposibles, según el filósofo Michael Tomasello.

En la Antigüedad se definía el estado original del alma como «tabula rasa», lo que significa que sus propiedades, contenidos y características no se agregaban sino con el paso del tiempo ${ }^{5}$. En griego, confluyen Physis (naturaleza) y Hexis (los bienes y la conducta), cuando Platón, en referencia a la educación de los guardianes constata en la República: «Las imitaciones, si se practican desde la juventud, se convierten en costumbres $y$, con ello, en naturaleza, tanto en relación al cuerpo o al lenguaje como a la mentalidad ${ }^{6}$. Con todo, para Aristóteles no basta la simple repetición; debe contarse, asimismo, con una disposición interna, una posesión relativa a la Hexis, un determinado comportamiento, que se mantiene ${ }^{7}$. Si Hexis es el haber, que también puede faltar, entonces, desde la perspectiva ontológica, Aristóteles se plantea si junto a la naturaleza puede haber, además, otra naturaleza y si es posible, hablando de la Hexis, que un sustrato posea determinados bienes y a la vez pueda heredar otros, aunque este deba poseerlos en su naturaleza completa ${ }^{8}$.

Nos referiremos a Aristóteles con más detalle por su condición de filósofo de referencia de la escolástica tardía del Siglo de Oro español. Mientras las virtudes intelectuales pueden, a su juicio, adquirirse por simple enseñanza, no sucede lo mismo con las virtudes morales, al conseguirse estas sólo mediante la costumbre. Mientras que en el acto de ver la costumbre ha seguido a la posesión, en el caso de las virtudes acontece lo contrario.

Las virtudes, por el contrario, las obtenemos tras una actividad precedente, como también es el caso de las artes porque lo que debemos hacer, después de haberlo aprendido, eso lo aprendemos en la medida en que lo hacemos. Así, mediante la construcción se forma el arquitecto, así

4 Tomasello, 2002, p. 24.

${ }^{5}$ Platón, Diálogos V, (Teeteto, 191 c); Aristóteles, Acerca del Alma III.

${ }^{6}$ Platón, Diálogos IV, (República III, 395d).

${ }^{7}$ Aristóteles, Retórica (I, 11, 1370 a; I, 10, 1369 b6).

${ }^{8}$ Aristóteles, Metafísica (V, 19-21, 1022 b 1-14); Aristóteles, Tratados de lógica (Órganon)/1, (Categorías, 10, 12 a 29). 
como tocando la cítara lo hace el citarista. De igual modo también nosotros nos convertimos en justos si obramos de forma justa, en comedidos, si actuamos de forma comedida o en resistentes si obramos con fuerza de voluntad ${ }^{9}$.

Sólo aquel que está acostumbrado a despreciar los peligros consigue la virtud de la valentía. El que es valiente podrá, en consecuencia, superar con más facilidad los peligros. Que la virtud no surge de la enseñanza, sino de la práctica, se pone asimismo de manifiesto en los dos siguientes pasajes de Aristóteles:

Para la virtud, sin embargo, el saber significa poco o nada. En cambio, lo que se adquiere tan sólo a través del ejercicio continuado de la justicia y la moderación, lejos de significar poco, lo significa todo. [...] Es lícito, por tanto, afirmar que a través de acciones justas uno se convierte en un hombre justo y a través de acciones moderadas, en un hombre moderado. Nadie que no las ejecute estará, por el contrario, en camino de convertirse en un hombre virtuoso ${ }^{10}$.

La virtud depende, por tanto, del desarrollo de un hábito que posibilita el buen comportamiento en relación con los afectos, lo que significa, por ejemplo, en el caso de la ira, encontrar el justo medio, no dejando que esta se haga excesiva. Por ello, Aristóteles define la virtud del hombre como un hábito que le permite ser bueno y orientar bien sus acciones. Precisamente este hábito debe entenderse en Aristóteles como una segunda naturaleza.

También en el contexto cristiano es conocida la doctrina de la segunda naturaleza, según la cual a una base innata debe añadirse lo aprendido, que, asimismo, se caracteriza por poder faltar. Para el aprendizaje de tales competencias, se dice en la Carta a los Hebreos del Nuevo Testamento, que a aquel que vive para el espíritu debe serle introducido, como el alimento, aquello que sirva al espíritu; de tal modo que lo sólido, frente a, por ejemplo, la leche materna, sólo es apto para aquellos cuyos sentidos, ejercitados por la costumbre, sean capaces de distinguir el bien del mal ${ }^{11}$. En relación a los Diez Mandamientos del

${ }^{9}$ Aristóteles, Ética nicomáquea, II 1103a, p. 161.

10 Aristóteles, Ética nicomáquea, II 1105b, p. 167.

11 Carta a los Hebreos, 5, 12-14. 
Antiguo Testamento formula Filón, aún de forma más marcada, que la costumbre continuada puede llegar a ser más fuerte que la naturaleza. Macrobius da testimonio de que el concepto de la segunda naturaleza se había generalizado para designar la costumbre en el contexto de la filosofia patrística cuando habla de "Consuetudo, quam secundam naturam pronuntiavit usus ${ }^{12}$. Una perspectiva algo distinta es la de San Agustín, cuando se refiere con la segunda naturaleza a la naturaleza de la humanidad desterrada del Paraíso tras el pecado original, designando, de este modo, como primera naturaleza la del hombre en el Edén. Con San Agustín y Santo Tomás el poder de la costumbre se relaciona con la necesidad de la gracia. Si el hombre desea sustituir las costumbres vitales del cuerpo por aquellas del espíritu, este necesitará, según San Agustín, ayuda sobrenatural, sin la cual tales hábitos no serían en absoluto alcanzables ${ }^{13}$. Puede distinguirse, por tanto, entre un habitus acquisitus, adquirido a través de una dedicación intensa, y un habitus infusus, que se da por influjo divino sobrenatural ${ }^{14}$. Juan de Pineda sitúa los «hábitos adquiridos» por encima de los «hábitos infusos» cuando habla de la virtud,

que se hace y torna como connatural al hombre y le conserva en el bien; porque, aunque los hábitos no confirmen al operante en sus actos, y aún los hábitos infusos no inclinen, según Escoto, a lo menos los adquiridos por costumbre, de los cuales se dice ser como segunda naturaleza, inclinan mucho a tales obras, cuales fueron aquellas que los engendraron; y ansí permanecen los virtuosos constantes en el ser de dependientes de la Iglesia $^{15}$.

Un problema especial surge en este sentido para Huarte cuando se cuestiona la posibilidad de una "sabiduría infusa» ${ }^{16} \mathrm{de}$ Cristo, partiendo de la base de que la inteligencia del Padre sólo puede ser resultado en el Hijo de una primera y no de una segunda naturaleza.

\footnotetext{
${ }^{12}$ Macrobius, Saturnalia, p. 429 (7, 9, 7).

${ }^{13}$ Agustín, Confessiones/ Bekenntnisse, VIII, 5.

14 Tomás de Aquino, Suma teológica, pp. 91-93.

${ }^{15}$ Pineda, Diálogos familiares de agricultura cristiana, pp. 285-286.

${ }^{16}$ Huarte, Examen de ingenios para las ciencias, p. 681.
} 
En su tratado sobre las costumbres y virtudes, Santo Tomás de Aquino explica que los hábitos, como el calor, que genera fuego, proceden de acciones

Porque todo lo que es pasivo y movido por otro, recibe una disposición por la actividad del agente. Por lo cual, la repetición de actos llega a formar en la potencia - en cuanto que es pasiva y movida - una cierta cualidad llamada hábito ${ }^{17}$.

En el artículo que sigue insiste, asimismo, en ello: "Acabamos de decir que el hábito se engendra por actos, en cuanto que la potencia pasiva es actuada por un principio activo ${ }^{18}$. Es como en el caso del fuego, que no quema inmediatamente el objeto, sino que va superando poco a poco las disposiciones que lo rehuyen y así, finalmente, las vence todas, sometiéndolas a su forma. El hábito es en sí para Santo Tomás una perfección que, sin embargo, puede crecer o disminuir cuantitativamente. Así como no toda alimentación conduce al crecimiento y fortalecimiento de un animal y no toda gota hace mella en la roca, tampoco es así con todas las acciones: "Repetidos los actos con igual o superior intensidad, se produce el aumento. En este mismo sentido, la repetición de actos aumenta los hábitos» ${ }^{19}$. Por el contrario, el decrecimiento de la intensidad de las acciones conduce a un debilitamiento del hábito. Por el contrario, cuando Santo Tomás distingue entre buenas y malas acciones, debe remitirse, sin embargo, a la naturaleza humana:

Se dice bueno o malo, según que disponga para un acto conveniente o no con la naturaleza del que obra; así, los actos de las virtudes son con-

17 Tomás de Aquino, Suma teológica, p. 88 («Nam omne quod patitur et movetur $\mathrm{ab}$ alio, disponitur per actum agentis: unde ex multiplicatis actibus generatur quaedam qualitas in potentia passiva et mota, quae nominatur habitus").

18 Tomás de Aquino, Suma teológica, p. 89 («Respondeo dicendum quod, sicut iam dictum est, habitus per actum generatur inquantum potentia passiva movetur ab aliquo principio activo»).

19 Tomás de Aquino, Suma teológica, p. 117 («sed, multiplicato alimento, tandem fit augmentum. Ita etiam, multi-plicatis actibus, crescit habitus"). 
venientes con la naturaleza humana; y los hábitos malos disponen a actos no convenientes con la misma 20 .

Como criterio de juicio de un hábito determinado se introduce, entonces, la naturaleza humana, que aquí, en el sentido aristotélico, como causa formal y final, hace referencia al mismo tiempo al ser y a la perfección del ser humano.

El hecho de que para el hombre sea necesaria, sobre todo, la práctica individual para alcanzar "sólidas virtudes»" ${ }^{21}$, lo subraya el fundador de la Compañia de Jesús, San Ignacio de Loyola,

Porque esforzándose de su parte en vencer a sí mismo y deshacer el amor propio, quitan con él las raíces de todas las pasiones y molestias; y también con alcanzar los hábitos virtuosos, vienen como naturalmente a obrar conforme a ellos, fácil y alegremente 22 .

En una de las reglas de los Ejercicios espirituales se distingue entre la disposición hacia lo negativo y una disposición hacia lo positivo,

porque entonces propio es del mal spíritu morder, tristar y poner impedimentos inquietando con falsas razones, para que no pase adelante; y propio del bueno dar ánimo y fuerzas, consolaciones, lágrimas, inspiraciones y quietud, facilitando y quitando todos impedimentos, para que el bien obrar proceda adelante ${ }^{23}$.

En otro pasaje San Ignacio modifica esta idea, distinguiendo entre distintos efectos de las disposiciones: "mucho mal a los que tienen la voluntad depravada y hábitos malos; mucho bien a los que tienen la

20 Tomás de Aquino, Suma teológica, p. 146 («Uno modo, secundum convenientiam ad naturam, vel etiam secundum disconvenientiam ab ipsa. [...] nam habitus bonus dicitur qui disponit ad actum convenientem naturae agentis; habitus autem malus dicitur qui disponit ad actum non convenientem naturae. Sicut actus virtutum naturae humanae conveniunt, eo quod sunt secundum rationem: actus vero vitiorum, cum sint contra rationem, a natura humana discordant.").

21 Loyola, Obras completas, p. 612; cómo «virtudes sólidas» se entiende: «paciencia, humildad, obediencia, abnegación de la voluntad propia, caridad», Loyola, Obras completas, p. 857.

${ }^{22}$ Loyola, Obras completas, p. 723.

23 Loyola, Obras completas, p. 227. 
voluntad toda a Dios N. S. aplicada y en buenos hábitos acostumbrada ${ }^{24}$. Es evidente, por tanto, que Calderón no sólo conoce las teorías de la segunda naturaleza de los filósofos de la Antigüedad y de la Escolástica, sino también las de los teólogos españoles del Siglo de Oro, al menos en su tiempo como estudiante de los Jesuitas.

En las discusiones filosóficas fuera de España, que se expondrán a continuación, surgieron dos cuestiones a partir de la presentación del alma como tabula rasa y de la adquisición de las virtudes éticas mediante la imitación y la costumbre: ¿Qué papel desempeñan las costumbres en la formación de la segunda naturaleza? ¿Existe, en realidad, la primera naturaleza? Si no existe nada procedente de la naturaleza que tenga validez, entonces, según el humanista francés Montaigne, las buenas costumbres extendidas entre la sociedad son las que hay que imitar y las que deben instaurarse como costumbre individual. Al igual que Plinio constata que «usus efficacissimus rerum omnium magister» ${ }^{25}$. Más tarde, Hegel caracterizará las costumbres desde la perspectiva del idealismo alemán como una segunda naturaleza, como un mundo de espíritu preestablecido en el que viven sujetos reales. Mientras la naturaleza es, según Hegel, algo ajeno a la conciencia, la segunda naturaleza es una naturaleza superior: «para el sujeto poseen la sustancia moral, sus leyes y su poder... una autoridad y un poder absolutos, infinitamente más firmes que el ser de la naturaleza» ${ }^{26}$. El hecho de que la segunda naturaleza sea más poderosa que la primera ya lo había puesto de manifiesto de forma lapidaria el jansenista francés Pascal cuando afirmaba que «la costumbre es una segunda naturaleza que destruye la primera» ${ }^{27}$. De ello no sólo extrae la conclusión del dominio de la segunda naturaleza sobre la primera, sino, asimismo, la cuestión de si la primera naturaleza debe distinguirse en absoluto de la segunda o incluso, de si quizás sólo existe una sola «segunda naturaleza» en propiedad: "Temo sinceramente que esta na-

${ }^{24}$ Loyola, Obras completas, p. 665.

25 Montaigne, Les Essais, 1, 23, Euvres, p. 106.

${ }^{26}$ Hegel, Grundlinien der Philosophie des Rechts oder Naturrecht und Staatswissenschaft im Grundrisse, $\ 146,7,228$ : «Für das Subjekt haben die sittliche Substanz, ihre Gesetze und Gewalten... eine absolute, unendlich festere Autorität und Macht als das Seyn der Natury.

27 Pascal, EEuvres complètes, Pensées, Fr. 120 (93): «La coutume est une seconde nature, qui détruit la première». 
turaleza no sea ella misma más que una primera costumbre como la costumbre es una segunda naturaleza ${ }^{28}$.

La segunda naturaleza se relaciona, por tanto, con la costumbre. Las costumbres, a su vez, están condicionadas por la repetición y la memoria. Puede distinguirse, por un lado, entre una costumbre subjetiva, que consiste, por ejemplo, en el fortalecimiento de lo espiritual y el debilitamiento de lo corporal y, por otro lado, una costumbre colectiva que, como uso, tiene un carácter obligatorio y normativo. A la adquisición subjetiva se opone la cotidianeidad objetiva. En este punto y para la ilustración de esta idea cabe mencionar al filósofo inglés Hobbes, para quien los objetos del mundo no son ni cuerpos ni movimientos, de tal modo que la costumbre influye en el surgimiento de un movimiento, en la ligera conducción del cuerpo en movimiento sobre un determinado camino ya preconfigurado, en el que las aversiones son evitadas y las inclinaciones satisfechas ${ }^{29}$. Para las costumbres subjetivas son especialmente significativos el ejercicio, la repetición y la memoria. A través de la repetición de determinadas acciones se conforman procesos de habituación y, con ellos, predisposiciones, que, finalmente, posibilitan el desarrollo de los mismos de forma prácticamente instintiva y al mismo tiempo automática, sin la correspondiente intervención de la decisión razonable. En el caso de la memoria, el humanista español Vives distingue entre memoria, recuerdo y reminiscencia, una distinción en la que nos detendremos más adelante ${ }^{30}$. Efectivamente es un mérito de la memoria que construya un hábito y una segunda naturaleza "porque la memoria le ayuda, no sólo para recibir fácilmente lo que se desea, sino para reproducirlo pronto y con fidelidad cuando sea necesario" ${ }^{31}$.

Además explica Vives que las acciones son generadas por capacidades. Aquellas, como la vista y el oído, por ejemplo, las posee ya el recién nacido y no necesitan practicarse para ser realizadas con éxito, "sino que tienen plena madurez y vigor, como amaestrados por vir-

${ }^{28}$ Pascal, Euvres complètes, Pensées, Fr. 120 (93): «'ai grand peur que cette nature ne soit elle-même qu'une première coutume, comme la coutume est une seconde nature».

${ }^{29}$ Hobbes, Vom Körper, p. $132(22,20)$.

${ }^{30}$ Vives, Tratado del alma, p. 60.

31 Vives, Tratado del alma, p. 60. 
tud de la naturaleza misma" ${ }^{32}$. Las acciones complejas, por el contrario, requieren, a juicio de Vives, práctica, ejercicio y costumbre «en la cual se reúnen facilidad para obrar y propensión, y viene del vocablo griego "Hexis", que corresponde al "habitus", o sea la inclinación a realizar actos semejantes a aquellos de los cuales se formón ${ }^{33}$. Al igual que el hábito puede sugerir o fijar acciones, también puede hacer lo mismo con las pasiones. Precisamente entonces es exigida la costumbre, cuando se trata de sobrellevar con facilidad «formas absurdas, repugnantes, y que causan miedo, o sonidos estupendos y horribles, sabores ácidos y amargos»" "De esa costumbre nacen la aptitud y facilidad en el artífice y la correspondiente adecuación en el instrumento" ${ }^{35}$.Vives toma como ejemplo al pintor, cuya mano sólo dirige el pincel de forma segura a través de la costumbre y la práctica. Sólo la costumbre lleva a la disposición adecuada para pintar. "Cuando un hábito se arraiga por el uso continuo adquiere casi fuerza de naturaleza, invitándonos a obrar de igual modo sin dificultad y hasta con gusto" ${ }^{36}$. La costumbre hace los asuntos de todos los días más agradables y hace también más llevadero lo desagradable. Por ello Vives considera especialmente importante escoger "el mejor método de vida [porque] "con la costumbre se hará llevadero", y según Platón es de gran importancia "el modo cómo se ha formado y acostumbrado cada uno desde la niñez" "37. Con ello, Vives subraya la relevancia de la práctica de un hábito para obrar correctamente. Define el hábito como piedra angular del alma «a fin de suministrarla mediante el uso y el ejercicio cuanto debemos hacer que sea recto y conveniente ${ }^{38}$. Si, en cambio, no fuera así que a través de la continuidad en el tiempo actuando en una misma dirección se fortaleciera una determinada capacidad, entonces se estaría siempre al principio, siendo imposible llevar a cabo una acción excelente.

Se ha mostrado, por tanto, que el concepto de segunda naturaleza, tal y como es concebido en la Antigüedad, está presente no sólo

\footnotetext{
32 Vives, Tratado del alma, pp. 112-113.

33 Vives, Tratado del alma, pp. 112-113.

34 Vives, Tratado del alma, pp. 112-113.

${ }^{35}$ Vives, Tratado del alma, pp. 112-113.

36 Vives, Tratado del alma, pp. 112-113.

37 Vives, Tratado del alma, pp. 112-113.

${ }^{38}$ Vives, Tratado del alma, pp. 112-113.
} 
en la literatura, sino también en la Filosofía y en la Teología del Siglo de Oro. Mateo Alemán presenta la relevancia y complejidad de la segunda naturaleza en la segunda parte del Guzmán de Alfarache de forma especialmente detallada, dado que para su pícaro no es imprescindible con qué acciones ha adquirido determinados hábitos. Se plantea la cuestión, entonces, de si le es posible oponerse al poder del tiempo y de la costumbre, pues la costumbre es poderosa, según Mateo Alemán, tanto para lo bueno como para lo malo:

Quita y pone leyes, fortaleciendo las unas y rompiendo las otras; prohíbe y establece, como poderoso príncipe, y consecutivamente a la parte que se acuesta, lleva tras de sí el edificio, tanto en el seguir los vicios, cuanto en ejercitar virtudes. [...] No hay fuerzas que la venzan y tiene dominio sobre todo caso. Algunos la llamaron segunda naturaleza, empero por experiencia nos muestra que aún tiene mayor poder, pues la corrompe y destruye con grandísima facilidad ${ }^{39}$.

La costumbre es tan fuerte que puede modificar el sentido del gusto: si lo amargo sabe bien, esto se debe sólo a la costumbre, que lo dulcifica. Para Mateo Alemán, sólo la costumbre, convertida en segunda naturaleza, hace posible al pastor resistir en campos abandonados, valles profundos o altas cumbres y montañas, en invierno, temporales, lluvia, rayos y truenos y, en verano, un sol de justicia que calienta piedras y metales. La costumbre es, a su juicio, tan fuerte como el sol. Mientras este último regala con su esplendor existencia y vida, la costumbre puede en silencio fortalecer, construir, destruir y «con las continuas gotas cavar las duras piedras ${ }^{40}$. Sólo el tiempo es más fuerte que la costumbre, del que esta depende. Unida al tiempo tiene tanto poder "que hace domesticarse las fieras más fieras y ponzoñosas, refrenando sus furias y mitigando sus venenos $\eta^{41}$. Todo esto, dice el protagonista, ha podido comprobarlo a través de la experiencia personal ${ }^{42}$. Las acciones del pícaro en la sociedad han acentuado sus costumbres y sus moralmente cuestionables hábitos. De otro modo su-

${ }^{39}$ Alemán, Guzmán de Alfarache, p. 107.

${ }^{40}$ Alemán, Guzmán de Alfarache, p. 109.

41 Alemán, Guzmán de Alfarache, p. 198.

42 "Todo lo dicho se verificó bien de mí, en proprios términos y casos» (Alemán, Guzmán de Alfarache, p. 109). 
cede con el que no ha tenido ocasión de llevar a cabo acciones en la sociedad y no le ha sido posible, con ello, desarrollar unas determinadas costumbres. Este se corresponde para Mateo Alemán con la imagen del animal salvaje, cuya rabia y violencia no ha sido domesticada por las buenas costumbres.

Aquí puede pensarse en Segismundo, cuando, por primera vez tras su estancia en la torre, es puesto a prueba en el palacio, sin haber tenido la oportunidad de desarrollar, a través de la acción en la sociedad, sus costumbres morales para bien o para mal. Tal y como el pícaro de Mateo Alemán ha convertido una mala costumbre en una segunda naturaleza, Segismundo no ha adoptado ninguna costumbre a través de la práctica, por lo que no está preparado para el desafio, pues mientras que en el campo del conocimiento alcanza la teoría, la formación de las virtudes morales depende de su ejercicio práctico. Cuán extraño es el mundo para Segismundo, encerrado en su torre, se pone de manifiesto ya desde un comienzo en su encuentro con Rosaura cuando ella le pregunta cómo es este: «tan poco del mundo sé, / que cuna y sepulcro fue / esta torre para mí» (vv. 194-196). Cuando describe el lugar en el que vive su encierro como «rústico desierto» hace prácticamente una alusión a la tabula rasa de su mundo de experiencias. Y cuando admite que todo aquello que sabe de la tierra y del cielo lo ha averiguado a través de la educación de una sola persona, a saber, Clotaldo, es natural que se describa a sí mismo como "un hombre de las fieras, / y una fiera de los hombres» (vv. 211-212). La costumbre de las relaciones sociales es lo que le falta. No ha aprendido la manera de gobernar un estado entre hombres, sino entre bestias: «la política he estudiado, / de los brutos enseñado" (vv. 214-215). Las letras humanas, dice Clotaldo, las ha aprendido Segismundo «de los montes y los cielos, en cuya divina escuela la retórica aprendió de las aves y las fieras» (vv. 1030-1033). Las primeras exclamaciones de Segismundo en el palacio, donde todo le resulta extraño, reflejan lo muy superado que se ve por la situación: «Válgame el cielo, qué veo! / Válgame el cielo, qué miro! / Con poco espanto lo admiro, con mucha duda lo creo. / Yo en palacios suntuosos? / Yo entre telas y brocados?» (vv. 1224-1228). Buena prueba de que Segismundo no está acostumbrado ni a límites ni a contemplaciones la da su paradigmática frase «No / me estorbe nadie, que es vana / diligencia, y ¡vive Dios! / si os ponéis delante vos, / que os eche por 
la ventana.» (vv. 1311-1315), que le hace ganarse reproches de soberbia por parte de Clotaldo. Continuamente se hace hincapié en que Segismundo se ha criado entre animales. Segismundo le reprocha a Basilio haberle repudiado, pues «como a una fiera me cría, / y como un monstruo me trata» (vv. 1482-1483). Posteriormente constatará «y sé que soy: / un compuesto de hombre y fiera" (vv. 1546-1547). Rosaura le negará a Segismundo la naturaleza humana: "Mas qué ha de hacer un hombre / que de humano no tiene más que el nombre, / atrevido, inhumano, / cruel, soberbio, bárbaro y tirano, / nacido entre las fieras?") (vv. 1654-1658).

Sus posteriores acciones serán descritas con enojo, rigor, rabia y cólera, características, por tanto, que tradicionalmente se atribuyen no a una segunda naturaleza del hombre bien construida, sino a la del animal incontrolado.

Si obviamos por un momento el hecho de que, según la investigación filosófica moderna, también los perros y los metales preciosos pueden tener una segunda naturaleza, podemos afirmar que la segunda naturaleza, en el contexto del Siglo de Oro, se ve restringida al ser humano. En este sentido, se remite sobre todo a Aristóteles, que no considera posible la existencia innata de las virtudes sin experiencia previa y estima el saber acerca de la virtud como poco importante, porque las virtudes sólo pueden adquirirse mediante el ejercicio continuado. Requisito para ello es la fijación de un hábito que se convierta en una segunda naturaleza. Sin el hábito el resultado de las acciones es casual e inseguro. Por ello, Ignacio de Loyola habla de sólidas virtudes y la discusión teológica confirma el enfoque filosófico y lo enriquece, en la medida en que introduce el concepto de la gracia divina. Ambas perspectivas culminan en la cuestión planteada por Pascal y, más tarde, por Hegel de si la segunda naturaleza domina sobre la primera o si incluso la destru ye. Fue Vives el que, siguiendo a Aristóteles, representó muy gráficamente, cómo a partir de la práctica desde la niñez surge el hábito y con él la personalidad orientada al obrar bien. Mateo Alemán mostró que la dura vida de un pastor sería difícil de resistir sin la formación de un hábito y que Segismundo es el ejemplo de que lo mismo es aplicable a la corte o a la vida en sociedad en general. A él no le era posible desarrollar entre animales un hábito adecuado que correspondiera a la segunda naturaleza propia del ser humano ya que las enseñanzas de Clotaldo eran sólo teó- 
ricas. La práctica, el ejercicio y la habituación, en cambio, no le fueron concedidas. De este modo, podemos concluir; en resumen, que Segismundo en su primera entrada en palacio no fracasa ni por una disposición negativa ni por las estrellas y sus vaticinios, sino simplemente, porque le faltaba la práctica necesaria para poder adquirir sus virtudes. Sin la formación de un hábito le falta la segunda naturaleza. Así actúa conforme a la naturaleza cuya praxis ha aprendido de los animales salvajes, que carecen de una segunda naturaleza. Desde esta perspectiva la pieza de Calderón constituye un alegato a favor de la vida en la corte y en sociedad y una prueba de las nocivas consecuencias que se originan al alejarse o vivir alejado de la sociedad humana. 


\section{Bibliografía}

Alemán, M., Guzmán de Alfarache, ed. S. Gili Gaya, Madrid, Espasa Calpe, 1936.

Aristóteles, Retórica, Madrid, Aguilar, 1968.

- Metafísica, Madrid, Gredos, 1998.

- Acerca del alma, Madrid, Gredos, 1999.

- Ética nicomáquea, Madrid, Gredos, 2000.

- Tratados de lógica (Órgano)/1: Categorias, Tópicos, Sobre las refutaciones sofisticas, Madrid, Gredos, 2000.

Calderón de la Barca, P., El divino Jasón, Kassel, Reichenberger, 2003.

- La vida es sueño, ed. D. Ynduráin, Madrid, Alianza, 2002.

Gracián, B., Oráculo manual y arte de prudencia, Madrid, Turner, 1995.

Hegel, G. W. F., Grundlinien der Philosophie des Rechts oder Naturrecht und Staatswissenschaft im Grundrisse, ed. H. Glockner, Stuttgart / Bad Cannstatt, Frommann, 1964.

Hobbes, T., Vom Körper, Hamburg, Felix Meiner, 1967.

Huarte de San Juan, J., Examen de ingenios para las ciencias, Madrid, Cátedra, 1989.

Loyola, I. de, Obras completas, Madrid, BAC, 1952.

Macrobius, A. T., Satumalia, ed. J. Willis, Leipzig, Teubner, 1963.

MCDowel, J., «Responses», en Reason and Nature: Lecture and Colloquium in

Münster 1999, ed. M. Willaschek, Münster, Lit Verlag, 2000, pp. 93-117.

Montaigne, M. de, Les Essais, Paris, Quadrige, 2004.

Pascal, B., CEuvres complètes, ed. J. Chevalier, Paris, Gallimard, 1954.

Pineda, J. de, Diálogos familiares de agricultura cristiana, Madrid, Atlas, 1963-1964.

Platón, Diálogos IV: República, Madrid, Gredos, 2006.

- Diálogos V: Paménides, Teeteto, Sofista, Político, Madrid, Gredos, 2006.

San Agustín, Confessiones / Bekenntnisse, Düsseldorf, Artemis and Winkler, 2004.

Santo Tomás de Aquino, Suma teológica, ed. S. Ramírez, Madrid, BAE, 1954.

Tomasello, M., Die kulturelle Entwicklung des menschlichen Denkens, Frankfurt,

Suhrkamp, 2002.

Vega, L. de, La Aradia, Madrid, Castalia, 1975.

Vives, L., Tratado del alma, Buenos Aires, Espasa Calpe, 1945. 